\title{
Comparison of NWP prognosis and local monitoring data from NPPs
}

\author{
P. ASTRUP ${ }^{1}$, T.K. MIKKELSEN ${ }^{1}$
}

\begin{abstract}
For four German nuclear power plant sites and for Risø, the site of the Danish nuclear research reactors now being decommissioned, Numerical Weather Predictions (NWP) of wind speed and direction have been compared to 10 minute averaged local measurements. For the German sites the comparison covers data for approximately three month, January to March 2009, for the Risø site for approximately two thirds of the year October 1998 to September 1999. For each site the comparison has been made for all measurement levels and both for the NWP analysis time and for the maximum available forecast time. Means and standard deviations of NWP minus measured data are given as tables for all measurement levels while scatter plots are presented for only a single measurement level at analysis time at each site. For Risø and for the site close to the North Sea plus for the inland site Philippsburg the predictions of wind speed are on average rather close to the measured, but for sites not far from the latter two, Krümmel respectively Obrigheim, the discrepancies are substantial.
\end{abstract}

\section{Introduction}

The purpose of this study was to investigate the difference between on-site measured wind speed and direction and numerical predictions of these data as delivered by the weather services. Having compiled a data base it might then be possible to characterise sites with a "deviation" factor or function that could be used for local correction of NWP data.

The results published here are a subset of those reported in Astrup and Mikkelsen (2010), where NWP to local measurement comparisons are given for seven German NPP sites and for the Danish Ris $\varnothing$ research reactor site. The NWP data covering the seven German NPP sites Neckarwestheim, Obrigheim, Philippsburg, Isar, Brokdorf, Brunsbüttel, and Krümmel and produced by the Austrian Meteorological and Geophysical Office, AMGO, consists of two daily sets of analysis plus hourly forecasts of up to 48 hours. The spatial resolution is approximately $10 \mathrm{~km}$. Together with ten minute averaged measured wind speeds and directions, temperatures and other meteorological parameters at the sites, the AMGO forecasts have been made available by Bundesamt für Strahlenschutz

\footnotetext{
1 Wind Energy Department, Ris $\emptyset$ - DTU, Frederiksborgvej 399, 4000 Roskilde, Denmark.
} 
(BfS), the German Federal Office for Radiation Protection. For the Ris $\varnothing$ site the NWP results are produced by the Danish Meteorological Institute (DMI) and consist of 4 daily sets of analysis and hourly forecasts up to 5 hours. The spatial resolution is here approximately $5.5 \mathrm{~km}$. Also here forecasts for up to 48 hours were originally received, but due to the 4 daily updates only forecasts up to 5 hours have been saved.

The NWP results are referred to the measurement sites by so called $\mathrm{r}^{-2}$ interpolation between the 4 nearest NWP points and to the measurement heights by vertical interpolation following similarity theory, van Ulden and Holtslag (1995), i.e. the differences between the NWP wind speed at the NWP levels and the similarity wind speeds at the same level heights - based on Monin-Obukhov length and friction velocity - are linearly interpolated to the measurement heights and the so obtained values are added to the similarity wind speeds calculated for these heights. Speed and direction differences are taken as NWP results minus measurements, the direction differences normalized to stay within plus minus 180 degrees.

\section{Risø}

The Ris $\varnothing$ site has the geographical coordinates $55.694^{\circ} \mathrm{N}, 12.088^{\circ} \mathrm{E}$ and is situated on a small peninsula in the Roskilde Fjord. The comparison NWP to mast data has been done for the analysis time and for the 5 hour forecast, for wind speed for three heights: $44.2 \mathrm{~m}, 76.6 \mathrm{~m}$, and $125.2 \mathrm{~m}$ above ground, and for wind direction at $76.6 \mathrm{~m}$ and $125.2 \mathrm{~m}$. Wind direction is not measured at $44.2 \mathrm{~m}$. The wind direction comparison is further split into measured wind speed at $44.2 \mathrm{~m}$ being above or below $5 \mathrm{~m} / \mathrm{s}$. Figure 1 shows plots for $76.6 \mathrm{~m}$ for the analysis hours while means and standard deviations for speed and direction differences for all heights are listed in Table I.

The NWP data for wind speed are as an average slightly under predicted but the difference to measured speed is increasing with height. The mean direction difference NWP minus measured is pretty low, below $5^{\circ}$ at analysis time, but with a standard deviation of approximately $25^{\circ}$ which however reduces to $15^{\circ}$ if only times with wind speeds above $5 \mathrm{~m} / \mathrm{s}$ at $44.2 \mathrm{~m}$ is taken into account. The 5 hour forecasts behave expectedly, both speed and direction standard deviations increase, although very little, and the 5 hour forecasts compare to data almost as well as the analysis time NWP results.

\section{German nuclear power plant sites}

Comparisons of NWP and measured wind speed and direction data are here presented for four of the seven sites considered in the overall study. Comparison 

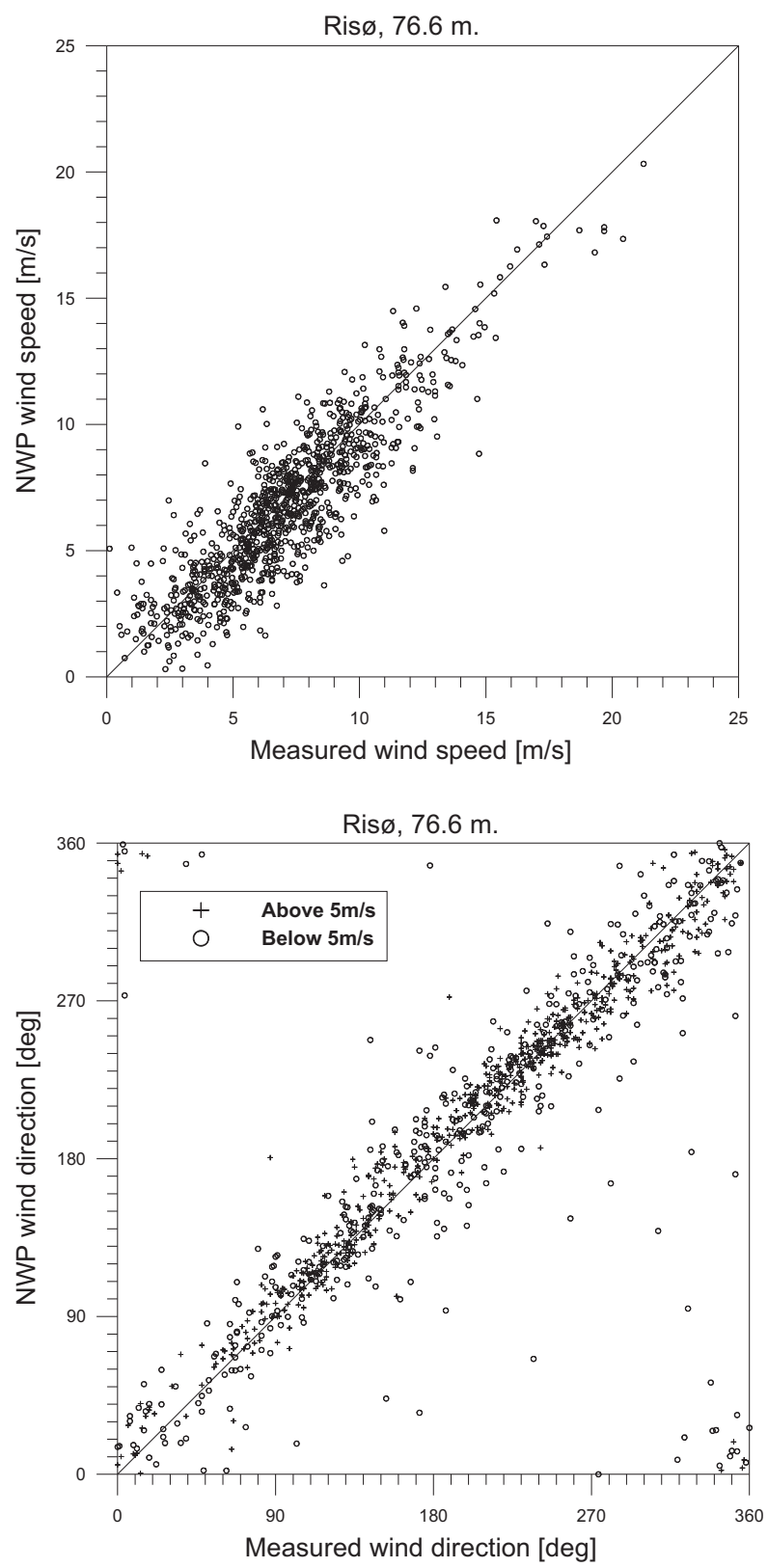

Figure 1 - 1017 sets of DMI HIRLAM results for Risø compared to measured data. Analysis time. 
TABLE I

Statistics of differences between DMI HIRLAM results and Risø data.

\begin{tabular}{|c|c|c|c|c|c|c|}
\hline \multirow{2}{*}{$\begin{array}{c}\text { Height } \\
{[\mathrm{m}]}\end{array}$} & \multicolumn{3}{|c|}{$\begin{array}{l}\text { Analysis time } \\
\text { speed diff }[\mathrm{m} / \mathrm{s}]\end{array}$} & \multicolumn{3}{|c|}{$\begin{array}{l}5 \text { hour forecast } \\
\text { speed diff }[\mathrm{m} / \mathrm{s}]\end{array}$} \\
\hline & mean & std.dev & count & mean & std.dev & count \\
\hline 44.2 & -0.167 & 1.375 & 1017 & 0.568 & 1.755 & 1015 \\
\hline 76.6 & -0.223 & 1.456 & 1010 & 0.527 & 1.869 & 1008 \\
\hline 125.2 & -0.579 & 1.553 & 1017 & 0.221 & 1.903 & 1015 \\
\hline Height & \multicolumn{3}{|c|}{ direction diff [deg] } & \multicolumn{3}{|c|}{ direction diff $[\mathrm{deg}]$} \\
\hline$[\mathrm{m}]$ & mean & std.dev & count & mean & std.dev & count \\
\hline 76.6 & 1.4 & 24.6 & 1017 & 6.4 & 27.0 & 1015 \\
\hline \multirow[t]{2}{*}{125.2} & 4.0 & 24.3 & 1017 & 7.9 & 25.4 & 1015 \\
\hline & \multicolumn{6}{|c|}{ Measured wind speed at $44.2 \mathrm{~m}<5 \mathrm{~m} / \mathrm{s}$} \\
\hline Height & \multicolumn{3}{|c|}{ direction diff $[\mathrm{deg}]$} & \multicolumn{3}{|c|}{ direction diff $[\mathrm{deg}]$} \\
\hline$[\mathrm{m}]$ & mean & std.dev & count & mean & std.dev & count \\
\hline 76.6 & 0.3 & 34.8 & 406 & 6.6 & 38.7 & 375 \\
\hline 125.2 & 1.4 & 35.1 & 406 & 6.6 & 37.3 & 375 \\
\hline & \multicolumn{6}{|c|}{ Measured wind speed at $44.2 \mathrm{~m}>5 \mathrm{~m} / \mathrm{s}$} \\
\hline Height & \multicolumn{3}{|c|}{ direction diff $[\mathrm{deg}]$} & \multicolumn{3}{|c|}{ direction diff [deg] } \\
\hline$[\mathrm{m}]$ & mean & std.dev & count & mean & std.dev & count \\
\hline 76.6 & 2.1 & 14.2 & 611 & 6.3 & 16.6 & 640 \\
\hline 125.2 & 5.7 & 12.5 & 611 & 8.7 & 14.3 & 640 \\
\hline
\end{tabular}

has been performed for the analysis time and for the 48 hour forecast. The reported site order ranges from north to south, i.e. Brokdorf, Krümmel, Obrigheim, and Philippsburg.

\section{Brokdorf}

The Brokdorf plant with the coordinates $53.851^{\circ} \mathrm{N}, 9.346^{\circ} \mathrm{E}$ is situated in flat terrain on the bank of the River Elbe approximately $25 \mathrm{~km}$ upstream from the rivers mouth at the North Sea coast.

There exist three measurement heights with $19 \mathrm{~m}, 60 \mathrm{~m}$ and $100 \mathrm{~m}$. Figure 2 shows the scatter plots of the numerical weather predictions versus the measured data at $100 \mathrm{~m}$, and Table II lists means and standard deviations of the differences.

The NWP wind speeds are on average pretty close to the measured ones, both at analysis time and at 48 hours forecast, the scatter growing reasonably with time. The NWP wind speeds are slightly over predicted at the lowest height, tending towards under prediction at $60 \mathrm{~m}$ and are generally somewhat under predicted at $100 \mathrm{~m}$. The difference is increasing with increasing measured wind speed. As 

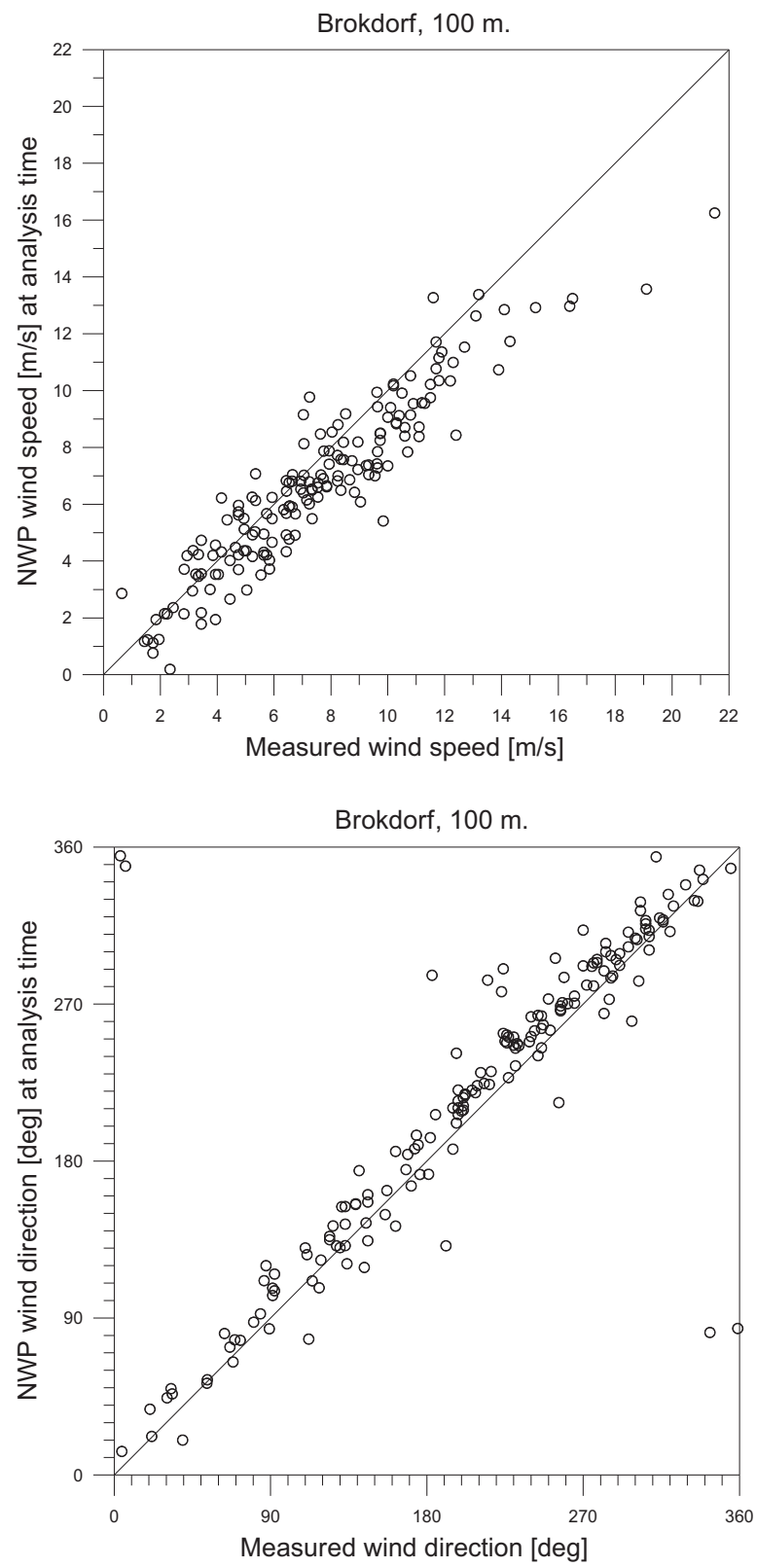

Figure 2 - NWP results for Brokdorf compared to measured data. Analysis time. 
TABLE II

Statistics of differences between NWP results and Brokdorf data.

\begin{tabular}{ccccccc}
\hline & \multicolumn{3}{c}{$\begin{array}{c}\text { Analysis time } \\
\text { speed diff [m/s] }\end{array}$} & & \multicolumn{3}{c}{$\begin{array}{c}\text { hour forecast } \\
\text { speed diff [m/s] }\end{array}$} \\
\hline Height & mean & std.dev & count & mean & std.dev & count \\
19.0 & 0.643 & 1.20 & 170 & 1.295 & 1.75 & 166 \\
60.0 & -0.274 & 1.34 & 167 & 0.392 & 1.91 & 163 \\
100.0 & -0.819 & 1.29 & 171 & -0.099 & 2.14 & 167 \\
Height & & direction diff $[\mathrm{deg}]$ & & & direction diff $[\mathrm{deg}]$ & \\
{$[\mathrm{m}]$} & mean & std.dev & count & mean & std.dev & count \\
19.0 & 14.299 & 23.67 & 170 & 13.253 & 36.31 & 166 \\
60.0 & 12.321 & 22.77 & 167 & 13.040 & 34.34 & 163 \\
100.0 & 10.848 & 19.67 & 171 & 10.495 & 34.59 & 167 \\
\hline
\end{tabular}

expected, but reasonably in number, the scatter, i.e. standard deviation, is higher at the 48 hours forecast compared to the analysis time. Wind directions are all slightly over predicted.

\section{Krümmel}

The Krümmel plant with the coordinates $53.411^{\circ} \mathrm{N}, 10.410^{\circ} \mathrm{E}$ is situated at the River Elbe approximately $85 \mathrm{~km}$ southeast of the Brokdorf plant and $30 \mathrm{~km}$ southeast of Hamburg and thus somewhat more inland than Brokdorf.

There are three measurement heights at Krümmel: $47 \mathrm{~m}, 85 \mathrm{~m}$ and $148 \mathrm{~m}$. Figure 3 shows two scatter plots of the numerical weather predictions versus the measured data, and Table III lists means and standard deviations of the differences.

The NWP results for Krümmel show large over predictions for wind speeds while wind directions are pretty close to the measured. Most but not all of the worst direction outliers correspond to very low wind speeds so selecting only winds with speeds above $1 \mathrm{~m} / \mathrm{s}$ results in a wind direction scatter somewhat smaller than for the whole set, most pronounced for the analysis time.

\section{Obrigheim}

The Obrigheim plant with the coordinates $49.364^{\circ} \mathrm{N}, 9.076^{\circ} \mathrm{E}$ is situated in the Southern part of Germany at the River Neckar, a tributary to the Rhine River. The meteorological measurements here are available at $20 \mathrm{~m}, 60 \mathrm{~m}$, and $80 \mathrm{~m}$ above ground. Figure 4 shows the scatter plots of the numerical weather predictions versus the measured data, Table IV provides the statistics. 
Krümmel, $85 \mathrm{~m}$.

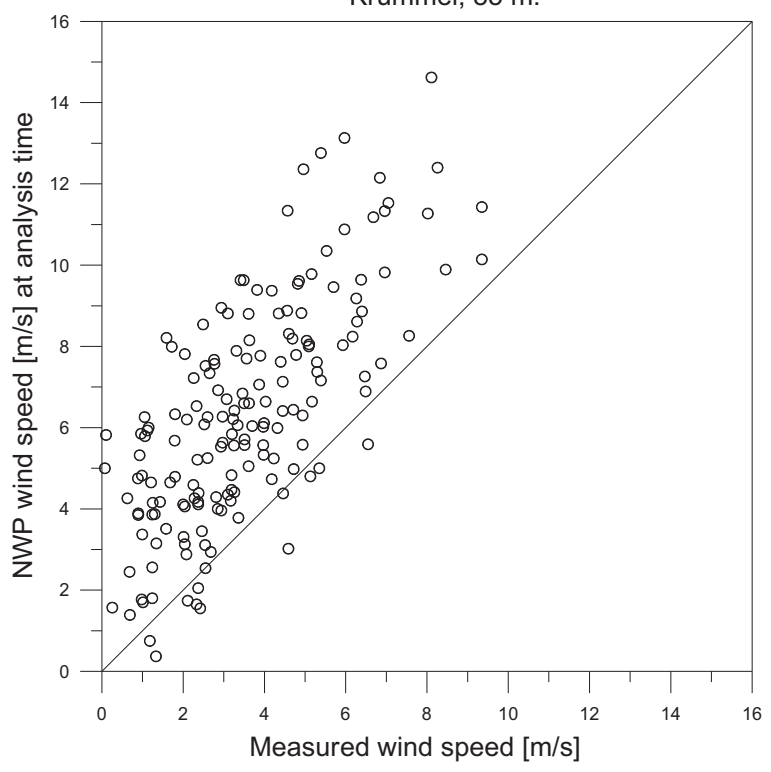

Krümmel, $85 \mathrm{~m}$.

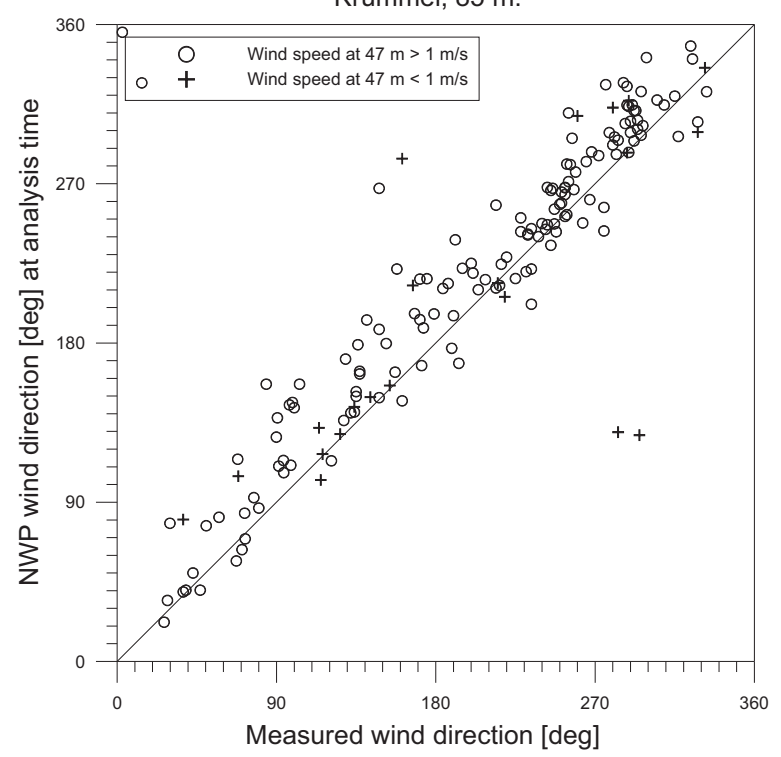

Figure 3 - NWP results for Krümmel compared to measured data. Analysis time. 
Obrigheim, $80 \mathrm{~m}$.
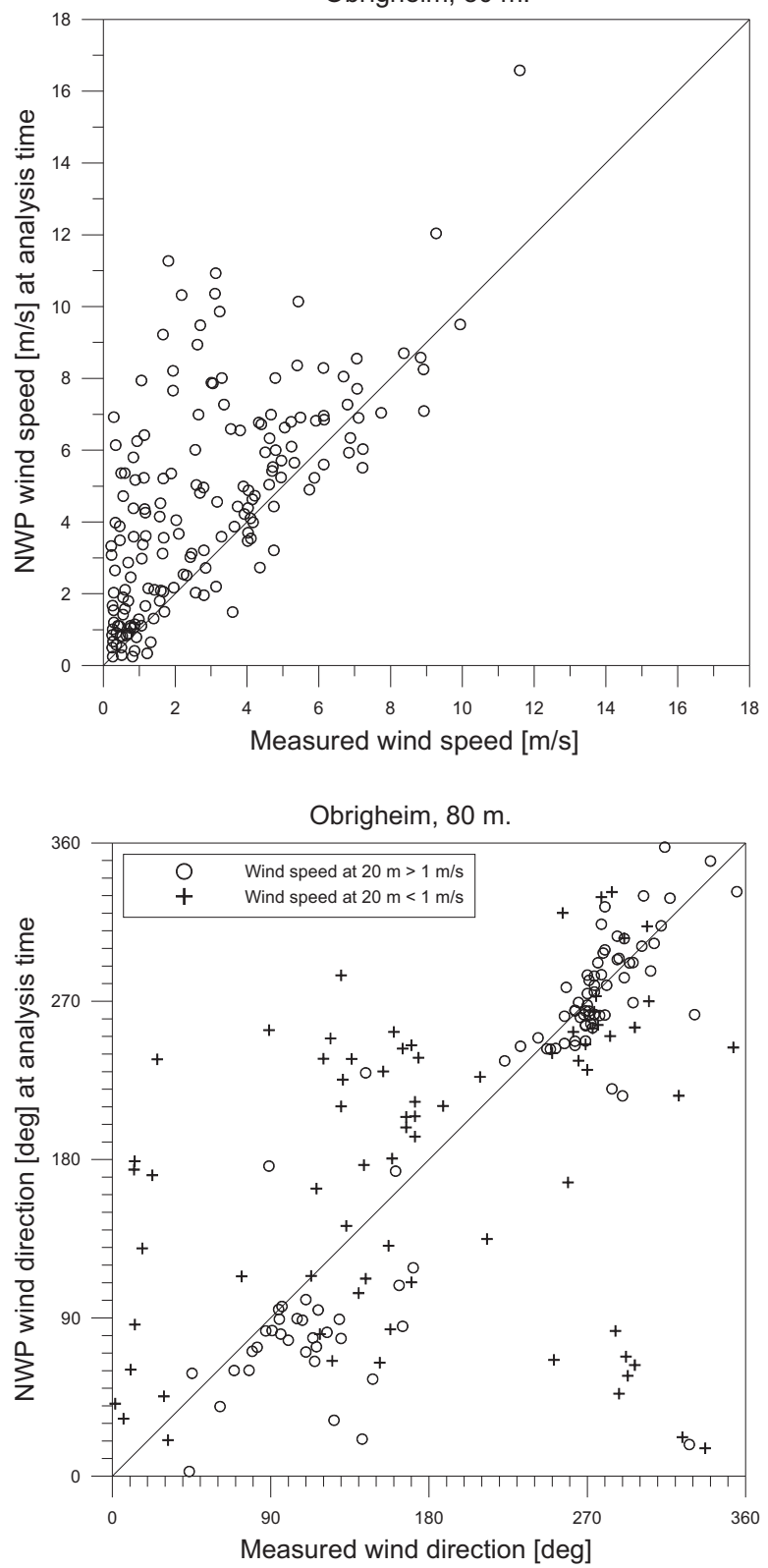

Figure 4-NWP results for Obrigheim compared to measured data. Analysis time. 
TABLE III

Statistics of differences between NWP results and Krümmel data.

\begin{tabular}{|c|c|c|c|c|c|c|}
\hline \multirow{2}{*}{$\begin{array}{l}\text { Height } \\
\text { [m] }\end{array}$} & \multicolumn{3}{|c|}{$\begin{array}{l}\text { Analysis time } \\
\text { speed diff }[\mathrm{m} / \mathrm{s}]\end{array}$} & \multicolumn{3}{|c|}{$\begin{array}{l}48 \text { hour forecast } \\
\text { speed diff }[\mathrm{m} / \mathrm{s}]\end{array}$} \\
\hline & mean & std.dev & count & mean & std.dev & count \\
\hline 47.0 & 3.091 & 1.72 & 169 & 3.913 & 2.24 & 165 \\
\hline 85.0 & 2.824 & 1.90 & 169 & 3.686 & 2.43 & 165 \\
\hline 148.0 & 0.875 & 2.25 & 169 & 1.689 & 2.62 & 165 \\
\hline Height & \multicolumn{3}{|c|}{ direction diff [deg] } & \multicolumn{3}{|c|}{ direction diff [deg] } \\
\hline$[\mathrm{m}]$ & mean & std.dev & count & mean & std.dev & count \\
\hline 47.0 & 11.359 & 31.54 & 169 & 12.228 & 35.05 & 165 \\
\hline 85.0 & 13.136 & 30.06 & 165 & 13.543 & 34.80 & 161 \\
\hline \multirow[t]{2}{*}{148.0} & 13.011 & 25.86 & 169 & 12.266 & 35.13 & 165 \\
\hline & \multicolumn{6}{|c|}{ Measured wind speed at $47 \mathrm{~m}>1 \mathrm{~m} / \mathrm{s}$} \\
\hline Height & \multicolumn{3}{|c|}{ direction diff [deg] } & \multicolumn{3}{|c|}{ direction diff [deg] } \\
\hline$[\mathrm{m}]$ & mean & std.dev & count & mean & std.dev & count \\
\hline 47.0 & 14.117 & 21.68 & 144 & 12.864 & 31.71 & 142 \\
\hline 85.0 & 14.881 & 21.72 & 144 & 14.335 & 31.78 & 142 \\
\hline 148.0 & 13.957 & 19.78 & 144 & 13.873 & 30.83 & 142 \\
\hline
\end{tabular}

TABLE IV

Statistics of differences between NWP results and Obrigheim data.

\begin{tabular}{|c|c|c|c|c|c|c|}
\hline \multirow{3}{*}{$\begin{array}{c}\text { Height } \\
{[\mathrm{m}]}\end{array}$} & \multicolumn{3}{|c|}{ Analysis time } & \multicolumn{3}{|c|}{48 hour forecast } \\
\hline & \multicolumn{3}{|c|}{ speed diff $[\mathrm{m} / \mathrm{s}]$} & \multicolumn{3}{|c|}{ speed diff $[\mathrm{m} / \mathrm{s}]$} \\
\hline & mean & std.dev & count & mean & std.dev & count \\
\hline 20.0 & 1.543 & 1.72 & 170 & 2.053 & 2.13 & 166 \\
\hline 60.0 & 1.467 & 2.11 & 169 & 2.022 & 2.63 & 165 \\
\hline 80.0 & 1.660 & 2.24 & 170 & 2.223 & 2.76 & 166 \\
\hline Height & \multicolumn{3}{|c|}{ direction diff [deg] } & \multicolumn{3}{|c|}{ direction diff [deg] } \\
\hline$[\mathrm{m}]$ & mean & std.dev & count & mean & std.dev & count \\
\hline 20.0 & -3.492 & 69.04 & 170 & -8.538 & 68.60 & 166 \\
\hline 60.0 & 31.256 & 86.79 & 169 & 24.783 & 84.84 & 165 \\
\hline \multirow[t]{2}{*}{80.0} & 8.002 & 57.90 & 170 & -4.714 & 61.75 & 166 \\
\hline & \multicolumn{6}{|c|}{ Measured wind speed at $20 \mathrm{~m}>1 \mathrm{~m} / \mathrm{s}$} \\
\hline Height & \multicolumn{3}{|c|}{ direction diff [deg] } & \multicolumn{3}{|c|}{ direction diff [deg] } \\
\hline [m] & mean & std.dev & count & mean & std.dev & count \\
\hline 20.0 & -5.041 & 34.65 & 97 & -13.737 & 40.27 & 93 \\
\hline 60.0 & 37.408 & 65.69 & 97 & 29.468 & 71.26 & 93 \\
\hline 80.0 & -9.368 & 32.00 & 97 & -17.343 & 37.60 & 93 \\
\hline
\end{tabular}


TABLE V

Statistics of differences between NWP results and Philippsburg data.

\begin{tabular}{|c|c|c|c|c|c|c|}
\hline \multirow{2}{*}{$\begin{array}{l}\text { Height } \\
{[\mathrm{m}]}\end{array}$} & \multicolumn{3}{|c|}{$\begin{array}{l}\text { Analysis time } \\
\text { speed diff }[\mathrm{m} / \mathrm{s}]\end{array}$} & \multicolumn{3}{|c|}{$\begin{array}{l}48 \text { hour forecast } \\
\text { speed diff }[\mathrm{m} / \mathrm{s}]\end{array}$} \\
\hline & mean & std.dev & count & mean & std.dev & count \\
\hline 15.0 & 0.334 & 1.00 & 170 & 0.854 & 1.37 & 166 \\
\hline 40.0 & 0.256 & 1.32 & 170 & 0.862 & 1.69 & 166 \\
\hline 120.0 & -0.357 & 1.42 & 170 & 0.210 & 1.95 & 166 \\
\hline Height & \multicolumn{3}{|c|}{ direction diff [deg] } & \multicolumn{3}{|c|}{ direction diff [deg] } \\
\hline$[\mathrm{m}]$ & mean & std.dev & count & mean & std.dev & count \\
\hline 15.0 & 20.124 & 45.46 & 170 & 12.269 & 49.63 & 166 \\
\hline 40.0 & 7.450 & 38.76 & 170 & 5.154 & 46.97 & 166 \\
\hline \multirow[t]{2}{*}{120.0} & 7.076 & 33.79 & 170 & 1.361 & 43.97 & 166 \\
\hline & \multicolumn{6}{|c|}{ Measured wind speed at $15 \mathrm{~m}>2 \mathrm{~m} / \mathrm{s}$} \\
\hline Height & \multicolumn{3}{|c|}{ direction diff [deg] } & \multicolumn{3}{|c|}{ direction diff [deg] } \\
\hline$[\mathrm{m}]$ & mean & std.dev & count & mean & std.dev & count \\
\hline 15.0 & 17.702 & 22.77 & 101 & 7.775 & 28.17 & 97 \\
\hline 40.0 & 6.481 & 20.08 & 101 & -2.357 & 26.07 & 97 \\
\hline 120.0 & 6.794 & 17.47 & 101 & -0.343 & 24.34 & 97 \\
\hline
\end{tabular}

The wind speeds are generally very low at Obrigheim, $45 \%$ of the measurements at $20 \mathrm{~m}$ are below $1 \mathrm{~m} / \mathrm{s}$. The NWP wind speeds are over predicted at all heights, and the standard deviation of the direction difference is very high, ranging from $55^{\circ}$ to $85^{\circ}$. When looking only at sets where the $20 \mathrm{~m}$ wind speed exceeds $1 \mathrm{~m} / \mathrm{s}$, the standard deviation of the direction difference is reduced to values between $30^{\circ}$ and $65^{\circ}$.

The average difference in wind direction at $60 \mathrm{~m}$ is $30^{\circ}$, but at 20 and $80 \mathrm{~m}$ only $3^{\circ}$ and $8^{\circ}$. Figure 5 shows scatter plots of the measured directions at 60 and $80 \mathrm{~m}$ against those measured at $20 \mathrm{~m}$, plus the equivalent figure for the NWP results. Although with great scatter, the $60 \mathrm{~m}$ measured directions seem to some extent to cluster approximately $30^{\circ}$ below the 20 and $80 \mathrm{~m}$ directions.

\section{Philippsburg}

Philippsburg at $49.2520^{\circ} \mathrm{N}, 8.4350^{\circ} \mathrm{E}$, is situated at the Rhine River approximately midway between Karlsruhe and Mannheim. Wind speeds and directions are measured at three heights: 15 m, 40 m, and 120 m. Figure 6 shows the scatter plots of the numerical weather predictions versus the measured data, and Table $\mathrm{V}$ lists means and standard deviations of their differences. 

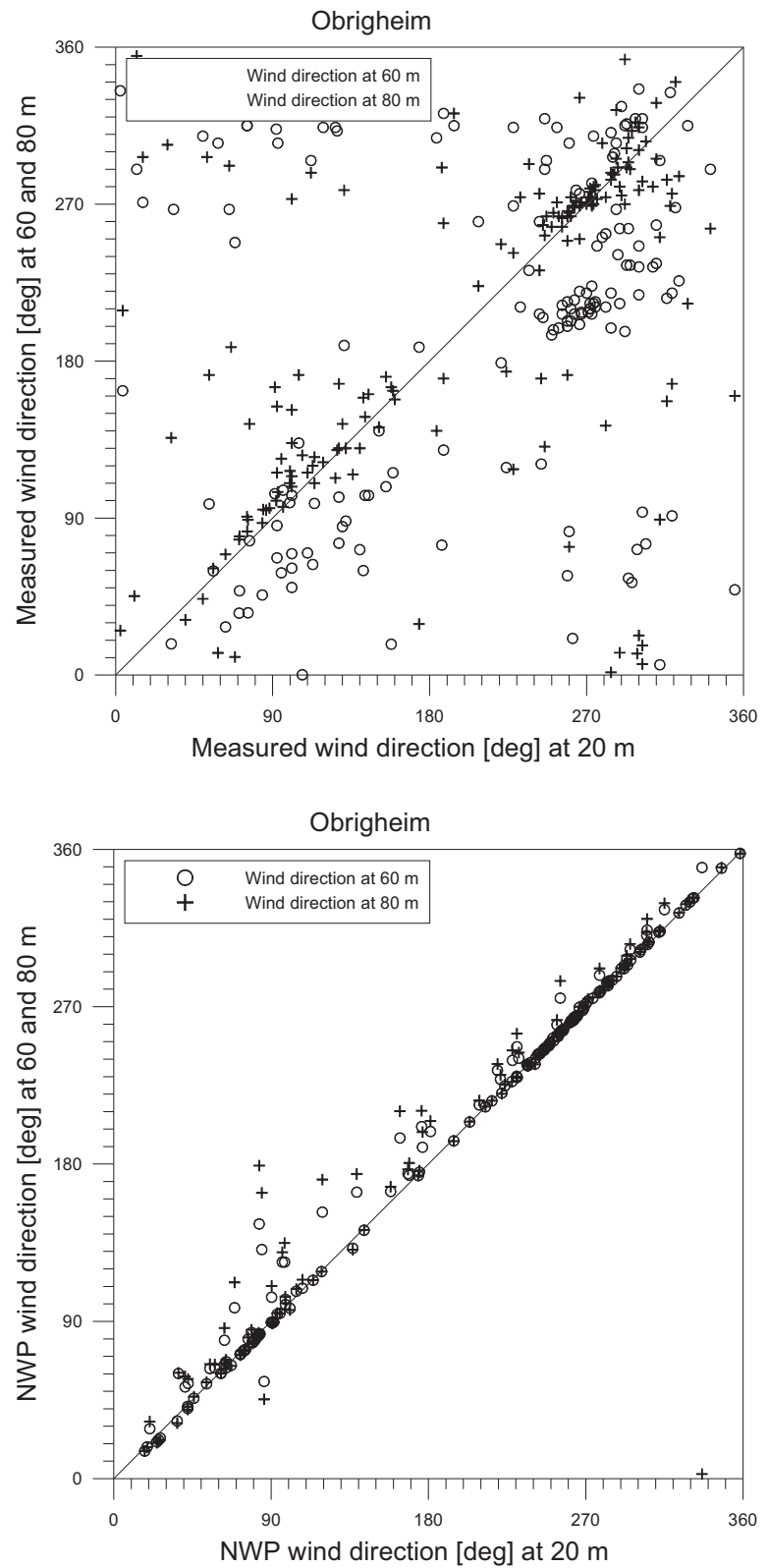

Figure 5 - Comparison of measured and predicted Obrigheim wind directions at 60 and 80 m to those at $20 \mathrm{~m}$. 
Philippsburg, $120 \mathrm{~m}$.

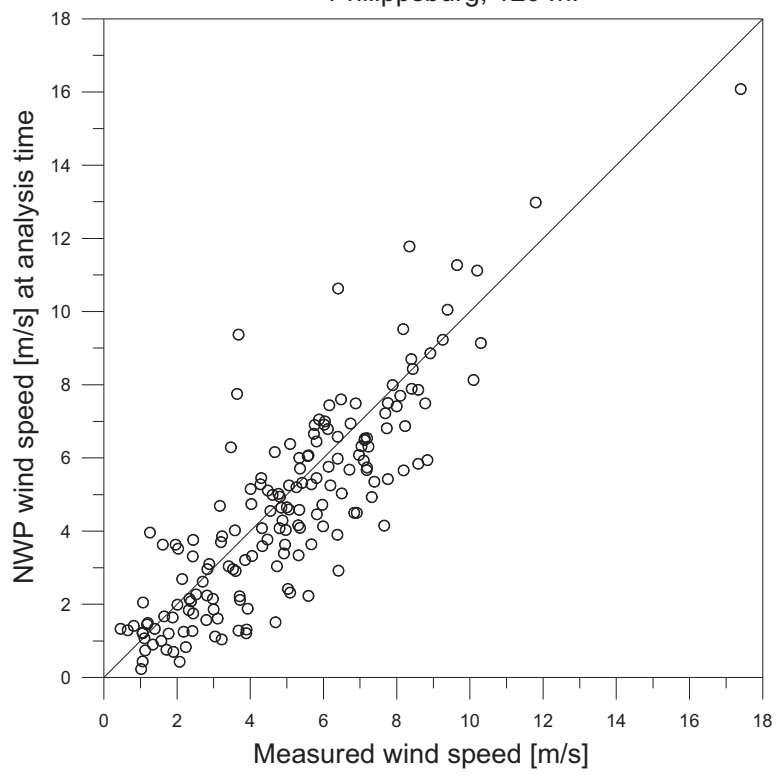

Philippsburg, $120 \mathrm{~m}$.

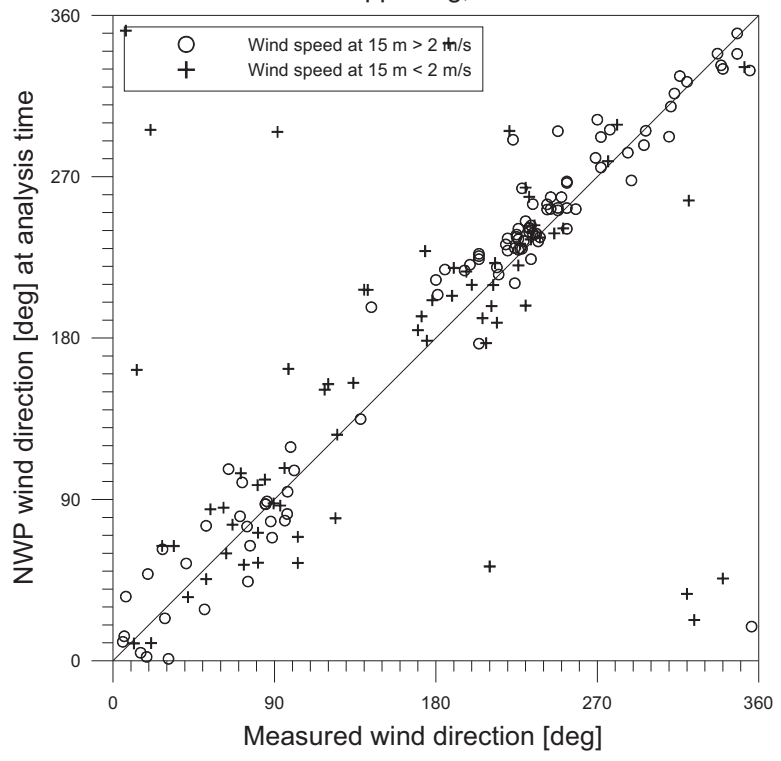

Figure 6 - NWP results for Philippsburg compared to measured data. Analysis time. 
The NWP wind speeds compare pretty well with the measurements although the lowest speeds are slightly under predicted. The mean wind direction differences are small, around $7^{\circ}$, except at $15 \mathrm{~m}$ where the difference is $12^{\circ}$. However, the standard deviations of the wind direction differences are large with values up to $45^{\circ}$. For a wind speed above $2 \mathrm{~m} / \mathrm{s}$ at $15 \mathrm{~m}$ this standard deviation of the direction however reduces to just around $20^{\circ}$.

\section{Brokdorf-Krümmel, Obrigheim-Philippsburg}

The NWP wind speeds at Brokdorf are very much the same as those at Krümmel, whereas those at Obrigheim are close to those of Philippsburg (see Fig. 7). This favours the assumption that the main reason for discrepancies between measured and predicted values are caused by local circumstances not resolved by the numerical models producing the NWP data.

\section{Conclusion}

Three month of data with wind speed and directions from twice per day delivered numerical weather predictions representing the analysis time and the 48 hours forecast time have been compared to measurements at four German nuclear power plant sites. In addition data from eight months were used in the comparison for the Danish Ris $\emptyset$ site for nuclear research reactors.

For the German site Brokdorf close to the North Sea and for the inland site Philippsburg the predictions of wind speed are on average rather close to the measured ones, but for sites not far from these, Krümmel respectively Obrigheim, the discrepancies are much larger. Concerning the wind directions the predicted values are on average almost everywhere larger than the measured, typically $15^{\circ}$ to $20^{\circ}$. Obrigheim is the only place with wind directions that were predicted with smaller values than measured. The scatter of the direction difference is pretty large at all sites, but taking into account only data sets for which the wind speed exceeds some limit, this scatter is reduced whereas the average discrepancies are not changing significantly. The relative large wind speed discrepancies at Krümmel and Obrigheim seem to be the result of local circumstances not resolved by the simulation models calculating the NWP data.

The $125 \mathrm{~m}$ meteorology mast at the Danish Ris $\varnothing$ site is placed on relative flat terrain just east of a reasonable large body of water and thus the terrain is comparable in complexity with that of Brokdorf. The differences between measurements and NWP data are also for Ris $\varnothing$ at the lower end thus making them comparable to the results for Brockdorf, even if the underlaying data base is different. 

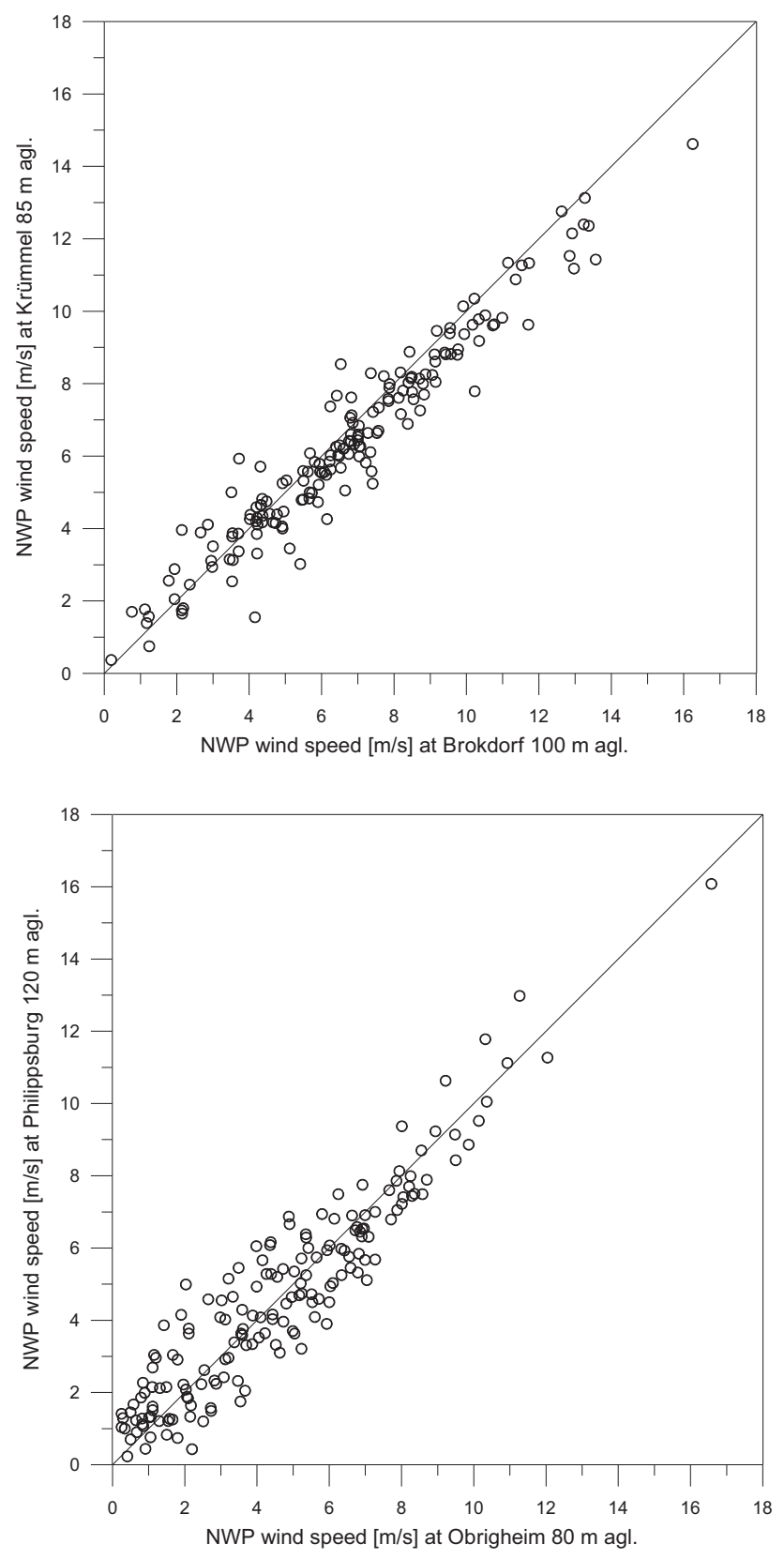

Figure 7 - Brokdorf to Krümmel and Obrigheim to Philippsburg NWP wind speed comparison. 
With this study it is in principle possible to derive an average "scaling factor" representing the deviation of on-site monitoring data to NWP data. Such a factor depends on the location of the site, e.g. if it is close to the coast or inland, but also on more local circumstances which cannot be substantiated just from a comparative study like this. For this reason each site of interest needs its own investigation. The wind speed also plays a role, and functions rather than factors may be needed to characterise the average deviation at the individual sites.

Acknowledgment. This work has received partial financial support from the European Commission Sixth Framework Programme (Nuclear Fission/Radiation Protection) under the EURANOS integrated project: European approach to nuclear and radiological emergency management and rehabilitation strategies (Contract No: FI6R-CT-2004-508843).

\section{REFERENCES}

Astrup P., Mikkelsen T.K. (2010) Comparison of NWP wind speeds and directions to measured wind speeds and directions. Ris $\emptyset-\mathrm{R}-1715(\mathrm{EN})$.

van Ulden A.P., Holtslag A.A.M. (1985) Estimation of Atmospheric Boundary Layer Parameters for Diffusion Applications, J.Clim. Appl. Meteorol. 24, 1196-1207. 